\title{
FREQUENCY OF REFRACTIVE ERROR AND AMBLYOPIA IN STRABISMUS IN PEDIATRIC AGE GROUP
}

\author{
Noureen Malik, Hannan Masud, Imran Basit, Palwasha Noor \\ Armed Forces Institute of Ophthalmology/National University of Medical Sciences (NUMS) Rawalpindi Pakistan
}

\begin{abstract}
Objective: To see the frequency and compare the type of refractive error and strabismus in amblyopic versus non amblyopic children.

Study Design: Comparative cross sectional study.

Place and Duration of Study: Armed Forces Institute of Ophthalmology, Rawalpindi, from Jan to Jul 2019.

Methodology: The sample population comprised of 250 patients of new or previously diagnosed children with refractive error and strabismus presenting at children eye outdoor patient department of armed forces institute of ophthalmology. Strabismus was diagnosed by the consultant eye specialist on the basis of heterotropia at near or distance fixation. Amblyopia and refracttive error was assessed by a trained optometrist. Patients were classified into amblyopia and non- amblyopia groups. The type of squint and refractive error was noted down along with demographic details. Chi square test was used to assess the significance of association between various categorical variables.

Results: A total of 250 participants were included with a mean age of $5.00 \pm 1.07$ years. Out of total, 132 (52.8\%) were males while 118 (47.2\%) were females. One hundred and fifty (59.5\%) patients were suffering from amblyopia while 100 (39.5\%) patients were normal with comparable vision in both the eyes. Out of 150 amblyopic patients 134 (89.3\%) were suffering from unilateral amblyopia while $16(10.6 \%)$ patients had amblyopia in both the eyes. Out of refractive errors astigmatism was present in $83(55.3 \%)$ of amblyopia patients while hypermetropia was present in $54(36 \%)$ of the patients. Out of total patients of strabismus, $95(63.3 \%)$ of non-alternating esotropic patients and $40(26.6 \%)$ of non-alternating exotropic patients were suffering from amblyopia.

Conclusion: Amblyopia was present in a significant number of patients suffering from both strabismus and refractive error. The most common refractive error present in amblyopic patients was astigmatism while most common type of strabismus associated with amblyopia was esotropia.
\end{abstract}

Keywords: Amblyopia, Refractive errors, Strabismus.

\footnotetext{
This is an Open Access article distributed under the terms of the Creative Commons Attribution License (http://creativecommons.org/licenses/by/4.0), which permits unrestricted use, distribution, and reproduction in any medium, provided the original work is properly cited.
}

\section{INTRODUCTION}

Amblyopia along with strabismus and refractive error is one of the most common visual problem which can lead to permanent visual disability ${ }^{1,2}$. Almost 1-5\% of children suffer from unilateral visual deterioration due to amblyopia worldwide 3,4 . The two most common causes of amblyopia are strabismus and refractive error. The permanent visual loss associated with amblyopia can be prevented by early and timely management of both these conditions ${ }^{5}$.

Pediatric ophthalmology is an underdeveloped specialty in our country and lack of sufficient number of trained pediatric ophthalmologists, most of pediatric disorders are being dealt with by general ophthalmologist. Strabismus is one of the common pediatric condition that need to be timely treated in order to prevent long term visual disability ${ }^{8,9}$.

Strabismus is one of the most common pediatric

Correspondence: Dr Hannan Masud, Classified Eye Specialist, Combined Military Hospital, Quetta Pakistan

Received: 13 Jul 2019; revised received: 12 Aug 2019; accepted: 19 Aug 2019 disorders all over the world and a lot of work has been done in developed countries to find the complications and associations of strabismus with other ocular and systemic disorders ${ }^{10}$. A meta-analysis of various studies conducted in recent past regarding strabismus and refractive errors concluded that myopia was a risk factor for exotropia and hyperopia has a dose related link with the presence of concomitant esotropia. Similarly the presence of three ocular comorbidities; strabismus, refractive errors and amblyopia has been studied in children with congenital ptosis and it was concluded that the these conditions were quite common and early recognition as well as treatment is necessary for better visual outcome.

Although a many studies have been conducted on the association of refractive errors with strabismus and amblyopia, but very limited data is available on the prevalence and association of type of refractive errors with type of strabismus in children suffering from amblyopia. This study was designed with the objective to look for refractive error and amblyopia and strabismus in pediatrics age group. 


\section{METHODOLOGY}

This comparative cross sectional study was conducted at the Armed forces institute of ophthalmology from January to July 2019. Sample size was calculated using WHO calculator. Keeping confidence level (1- $\alpha)$ at $95 \%$, absolute precision (d) at 0.06 , anticipated population proportion $(p)$ at $0.38,16$ a total sample size of 250 was calculated. Non probability consecutive sampling technique was used. The ethical approval of this study was taken from hospital ethics committee. All the patients between the age of 4 and 16, suffering from strabismus and refractive errors were included in the study. Informed written consent was taken from the parents and guardians before registering the patients in this study. Patients who were suffering from refractive errors and horizontal strabismus of at least more than 15 prism diopters were included. All those patients with vertical or noncomitant squint, ptosis, ocular trauma, media opacity, retinal pathology or history of previous ocular surgery were excluded.

The demographic details of all the registered patients were noted on a predesigned research Performa. Strabismus was diagnosed by consultant ophthalmologist on the basis of ocular alignment. All the registered children were evaluated using the alternate prism cover test with fixation targets at $4 \mathrm{~m}$ distance. Following this, a detailed slit lamp examination was carried out to look for any other confounding ocular pathology which can cause visual loss or strabismus. Patients were labeled as alternating esotropia, no alternating esotropia, alternating exotrpia or non-alternating exotropia. All the patients were evaluated by well-trained optometrist to assess the visual acuity, best corrected visual acuity (BCVA), type of refractive error with dard devia-tion was calculated for continuous variables such as age while frequency and percentages were calculated for refractive errors and strabismus in both amblyopia and non-amblyopia group. Chi-square was used to assess the association of categorical variables such as refractive error and strabismus with amblyopia. $p$-value of $\leq 0.05$ was considered as significant.

\section{RESULTS}

A total of 250 participants were included in the final analysis after the application of inclusion/exclusion criteria. Age of the patients varied from 3.50 years to 7 years with a mean age of $5.00 \pm 1.07$ years. Out of total, $132(52.8 \%)$ were males while $118(47.2 \%)$ were females. One hundred and fifty (59.5\%) patients were suffering from amblyopia while 100 (39.5\%) patients were normal with comparable vision in both the eyes and no amblyopia. Out of 150 amblyopic patients

Table-I: Gender-wise distribution of strabismus, refractive error and amblyopia.

\begin{tabular}{|c|c|c|c|}
\hline & \multicolumn{2}{|c|}{ Gender $(n=250)$} \\
\hline & & Males (\%) & Female (\%) \\
\hline \multirow{2}{*}{ Amblyopia } & Amblyopia & $33(13.2)$ & $117(46.8)$ \\
\hline & Non amblyopia & 99 (39.6) & $1(0.4)$ \\
\hline \multirow{3}{*}{$\begin{array}{l}\text { Refractive } \\
\text { error }\end{array}$} & Hypermetropia & $28(11.2)$ & $97(38.8)$ \\
\hline & Myopia & $24(9.6)$ & $20(8)$ \\
\hline & Astigmatism & $80(32)$ & $1(0.4)$ \\
\hline \multirow{4}{*}{ Strabismus } & $\begin{array}{l}\text { Alternating } \\
\text { esotropia }\end{array}$ & 33 (13.2) & - \\
\hline & $\begin{array}{c}\text { Non alternating } \\
\text { esotropia }\end{array}$ & $33(13.3)$ & $68(27.2)$ \\
\hline & $\begin{array}{c}\text { Alternating } \\
\text { exotropia }\end{array}$ & $66(26.4)$ & $1(0.4)$ \\
\hline & $\begin{array}{c}\text { Non alternating } \\
\text { exotropia }\end{array}$ & - & 49 (19.6) \\
\hline
\end{tabular}

Table-II: Association of amblyopia with type of refractive error.

\begin{tabular}{|c|c|c|c|c|c|}
\hline & \multicolumn{5}{|c|}{ Refractive Error $(n=250)$} \\
\hline & Hypermetropia (\%) & \multicolumn{2}{|c|}{\begin{tabular}{l|l} 
Myopia (\%) & \\
\end{tabular}} & Astigmatism (\%) & $p$-value \\
\hline Amblyopia & $54(36 \%)$ & \multicolumn{2}{|c|}{$13(8.6 \%)$} & $83(55.3 \%)$ & \multirow{2}{*}{0.01} \\
\hline Non Amblyopia & $14(14 \%)$ & \multicolumn{2}{|c|}{\begin{tabular}{l|l} 
& $14(14 \%)$ \\
\end{tabular}} & $72(72 \%)$ & \\
\hline \multicolumn{6}{|c|}{ Table-III: Association of amblyopia with type of strabismus. } \\
\hline & \multicolumn{4}{|c|}{ Strabismus $(\mathrm{n}=250)$} & \multirow[b]{2}{*}{$p$-value } \\
\hline & $\begin{array}{c}\text { Alternating } \\
\text { esotropia }\end{array}$ & $\begin{array}{c}\text { Non alternating } \\
\text { esotropia }\end{array}$ & $\begin{array}{c}\text { Alternating } \\
\text { exotropia }\end{array}$ & $\begin{array}{c}\text { Non alternating } \\
\text { exotropia }\end{array}$ & \\
\hline Amblyopia & $6(4 \%)$ & $95(63.3 \%)$ & $9(6 \%)$ & $40(26.6 \%)$ & \multirow[t]{2}{*}{$<0.01$} \\
\hline Non Amblyopia & $30(30 \%)$ & $3(3 \%)$ & $63(63 \%)$ & $4(4 \%)$ & \\
\hline
\end{tabular}

and without cycloplegic refraction. The patients were then categorized into amblyopia and non-amblyopia groups on the basis of BCVA.

Statistical analysis required for the study data was performed by using the SPSS-23. Mean and stan-
$134(89.4 \%)$ were suffering from unilateral amblyopia while $16(10.6 \%)$ patients had amblyopia in both the eyes. Table-I shows the gender wise distribution of amblyopia, refractive error and strabismus. Table-II shows the association of amblyopia with different 
types of refractive errors while table-III shows the association of amblyopia with strabismus. The most common refractive error was astigmatism 83 (55.3\%) while the refractive error most commonly associated with amblyopia was hypermetropia. The most common type of strabismus was non alternating esotropia. The most commonly associated type of strabismus associated with amblyopia was non alternating esotropia.

\section{DISCUSSION}

Early recognition of the ocular problems has usually been the key to counter them effectively. Various study have concluded that structural abnormalities of eye if picked up and corrected early are associated with good outcome in adulthood as compared to those whose treatment has been delayed. The presence of refractive error and strabismus are one of the two most common causative factors in the development of amblyopia. Zhu et al, concluded that uncorrected refractive error is more important factor than deviation ${ }^{11-16}$.

Out of total, more than half of our patients were suffering from amblyopia in one eye. Only six patients were having amblyopia in both the eyes. We analyzed the type of refractive error in both amblyopia and nonamblyopia groups. The most common refractive error in our patient was astigmatism and it accounted for 83 $(55.3 \%)$ more than half of the total patients. Out of total patients of amblyopia, astigmatism was the most common refractive error accounting for $83(55.4 \%)$ patients while hypermetropia was the second most common. Hypermetropia was present in $54(36 \%)$ of the patients. Mocanu et al, conducted a study in Eastern Europe while few other studies that are conducted in Australian pediatric population found the similar results. They also concluded astigmatism as the most frequently occurring refractive error followed by hypermetropia in amblyopic patients ${ }^{16-19}$. Presence of astigmatism in the patients of strabismus was strongly linked with presence of amblyopia in these patients. Results of studies done by Robaei et al18, and Shapira et al20, have produced similar results. Astigmatism is a refractive error and may share common abnormality pathway with amblyopia. Refractive errors need a separate mode of management while strabismus needs separate management. However, both the conditions may aggravate the misery of the patient and can be disastrous if the pediatric patient grows with both of these abnormalities simultaneously.

The prevalence and association of type of strabismus with amblyopia was the second most important objective of our study. We found out that the most common type of strabismus associated with amblyopia is esotropia. Out of total 150 patients, 101 patients were suffering from esotropia and the non-alternating esotropia where there is unilateral fixation preference was predominantly related with amblyopia while alternating esotropia has lesser risk of amblyopia. Forty nine patients of amblyopia were suffering from exotropia predominantly non alternating. Friedman et al ${ }^{10}$, and Chen et al ${ }^{19}$, have also studied the association of type of strabismus with the amblyopia. Another interesting study carried out by Shapira et al, on adult population concluded that timely screening of these problems during childhood improved utility of treatment for amblyopia and strabismus and early treatment was significantly linked with altering the natural course of these diseases ${ }^{20}$

\section{LIMITATION OF STUDY}

This study had many limitations. First of all study design and sample size pose methodological issues. Patients were picked from a military setting instead of a public care hospital which is a main obstacle in generalizability of the results. Moreover, studies with large sample size conducted at various centers and part of the population could have generated more comprehensive and reliable results.

\section{CONCLUSION}

Considering the results of this comparative cross sectional survey it is concluded that refractive errors and strabismus are the two significant factors in development of amblyopia. More than half of the patients suffering from these disorders develop amblyopia which can result in permanent visual disability. Among the refractive errors, astigmatism and among the strabismus non-alternating esotropia has highest association with development of amblyopia.

\section{CONFLICT OF INTEREST}

This study has no conflict of interest to be declared by any author.

\section{REFERENCES}

1. Robaei D, Kifley A, Rose KA, Mitchell P. Impact of amblyopia on vision at age 12 years: findings from a population-based study. Eye (Lond) 2008; 22(4): 496-02.

2. Friedman DS, Repka MX, Katz J, Giordano L, Ibironke J. Prevalence of amblyopia and strabismus in white and African American children aged 6 through 71 months the Baltimore Pediatric Eye Disease Study. Ophthalmol 2009; 116(11): 2128-34.

3. Chia A, Dirani M, Chan YH, Gazzard G, Au Eong KG, Selvaraj $\mathrm{P}$, et al. Prevalence of amblyopia and strabismus in young 
singaporean chinese children. Invest Ophthalmol Vis Sci 2010; 51(7): 3411-17.

4. Robaei D, Huynh SC, Kifley A. Correctable and non-correctable visual impairment in a population-based sample of 12-year-old Australian children. Am J Ophthalmol 2006; 142(1): 112-18.

5. Solebo AL, Cumberland PM, Rahi JS. Whole-population vision screening in children aged $4-5$ years to detect amblyopia. Lancet 2015; 385(9984): 2308-19.

6. Achigbu EO, Oguego NC, Achigbu K. Spectrum of Eye Disorders Seen in a Pediatric Eye Clinic South East Nigeria. Niger J Surg. 2017; 23(2):125-9. DOI: 10.4103/njs.NJS_37_16

7. Mehari ZA. Pattern of childhood ocular morbidity in rural eye hospital, Central Ethiopia. BMC Ophthalmol 2014; 14(1): 50-56.

8. Hashemi H, Fotouhi A, Yekta A, Pakzad R, Ostadimoghaddam $\mathrm{H}$, Khabazkhoob M. Global and regional estimates of prevalence of refractive errors: Systematic review and meta-analysis. J Curr Ophthalmol 2018; 30(1): 3-22.

9. Hussain A, Awan H, Khan MD. Prevalence of non-vision-impairing conditions in a village in Chakwal district, Punjab, Pakistan. Ophthalmic Epidemiol 2004; 11(5): 413-26.

10. Khorrami-Nejad M, Akbari MR, Khosravi B. The prevalence of strabismus types in strabismic Iranian patients. Clin Optom (Auckl) 2018; 10(2):19-24.

11. Mocanu V, Horhat R. Prevalence and risk factors of amblyopia among refractive errors in an eastern european population. Medicina (Kaunas) 2018; 54(1): 6-15.

12. Rao GN, Sabnam S, Pal S, Rizwan H, Thakur B, Pal A. Prevalence of ocular morbidity among children aged 17 years or younger in the eastern India. Clin Ophthalmol 2018; 12(9): 1645-52.

13. Tang SM, Chan RY, Bin Lin S, Rong SS, Lau HH, Lau WW, et al. Refractive Errors and Concomitant Strabismus: A Systematic Review and Meta-analysis. Sci Rep 2016; 6(10): 35177-80.

14. Wang Y, Xu Y, Liu X, Lou L, Ye J. Amblyopia, Strabismus and Refractive Errors in Congenital Ptosis: a systematic review and meta-analysis. Sci Rep 2018; 8(1): 8320-24.

15. Al-Tamimi ER, Shakeel A, Yassin SA, Ali SI. A clinic-based study of refractive errors, strabismus, and amblyopia in pediatric agegroup. J Family Community Med 2015; 22(3): 158-62.

16. Zhu H, Pan C, Sun Q, Huang D, Fu Z, Wang J, et al. Prevalence of amblyopia and strabismus in Hani school children in rural southwest China: a cross-sectional study. BMJ Open 2019; 9(2): e025441-45.

17. Pai AS, Rose KA, Leone JF, Sharbini S, Burlutsky G, Varma R, et al. Amblyopia prevalence and risk factors in Australian preschool children. Ophthalmol 2012; 119(1): 138-44.

18. Robaei D, Rose KA, Ojaimi E, Kifley A, Martin FJ, Mitchell P. Causes and associations of amblyopia in a population-based sample of 6-year-old Australian children. Arch Ophthalmol 2006; 124(6): 878-84.

19. Chen X, Fu Z, Yu J, Ding H, Bai J, Chen J, et al. Prevalence of amblyopia and strabismus in Eastern China: results from screening of preschool children aged 36-72 months. Br J Ophthalmol 2016; 100(4): 515-19.

20. Shapira Y, Machluf Y, Mimouni M, Chaiter Y, Mezer E. Amblyopia and strabismus: trends in prevalence and risk factors among young adults in Israel. Br J Ophthalmol 2018; 102(5): 659-66. 